\title{
Application of Innovative Technologies for Active Control and Energy Efficiency in Water Supply Systems
}

\author{
Armando Carravetta ${ }^{1, *\left(\mathbb{D}, \text { Maurizio Giugni }^{1} \text { and Stefano Malavasi }\right.}{ }^{2}$ \\ 1 Department of Civil, Architectural and Environmental Engineering, University Federico II of Naples, \\ 80125 Naples, Italy; giugni@unina.it \\ 2 Department of Civil and Environmental Engineering, Politecnico di Milano, Piazza Leonardo da Vinci 32, \\ 20133 Milano, Italy; stefano.malavasi@polimi.it \\ * Correspondence: armando.carravetta@unina.it
}

Received: 17 November 2020; Accepted: 18 November 2020; Published: 22 November 2020

\section{Introduction}

The larger anthropic pressure on the Water Supply Systems (WSS) and the increasing concern for the sustainability of the large energy use for water supply, transportation, distribution, drainage and treatment are determining a new perspective in the management of water systems. Operations on drinking, storm, waste and irrigation waters are now considered; likewise, so are any other industrial processes. Hence, an industrial approach is required and is starting to be implemented. The control of these systems is increasing through better connectivity, larger data acquisition, more process analysis and higher system control (Figure 1 [1]). An effort is also in action to move from the linear economy model to the circular economy model. In this perspective, the potentiality for the recycling of renewable and non-renewable sources is limited to few aspects of the process, as in the use of unconventional energy and water sources in presence of water scarcity, or in the reuse of the wastewater and the sludge coming from treatment plants. Much more emphasis should be given in the management of the water systems and product innovation. The use of new devices in the network affects the system sustainability in two ways: (i) it allows savings in the primary natural sources used by the system and in the framework of the water-energy-food nexus; (ii) it automatically incorporates in the water system all the environmental benefits expected at a political level by the product change. As an example, we can consider the recent change in the pump market determined by the European Community standards on Ecodesign. The pumps on the market are classified by a new performance index, the Minimum Efficiency Index (MEI) and a minimum value MEI $=0.4$ is required by Regulation (EU) No. 547/2012. This value was fixed by the European Commission on the basis of an expectation of the reduction in energy use of the pumps on the market. Then, the substitution of the existing pumps by a water utility with a new product will reduce the energy use of the system and will contribute to reach the EC environmental target. 


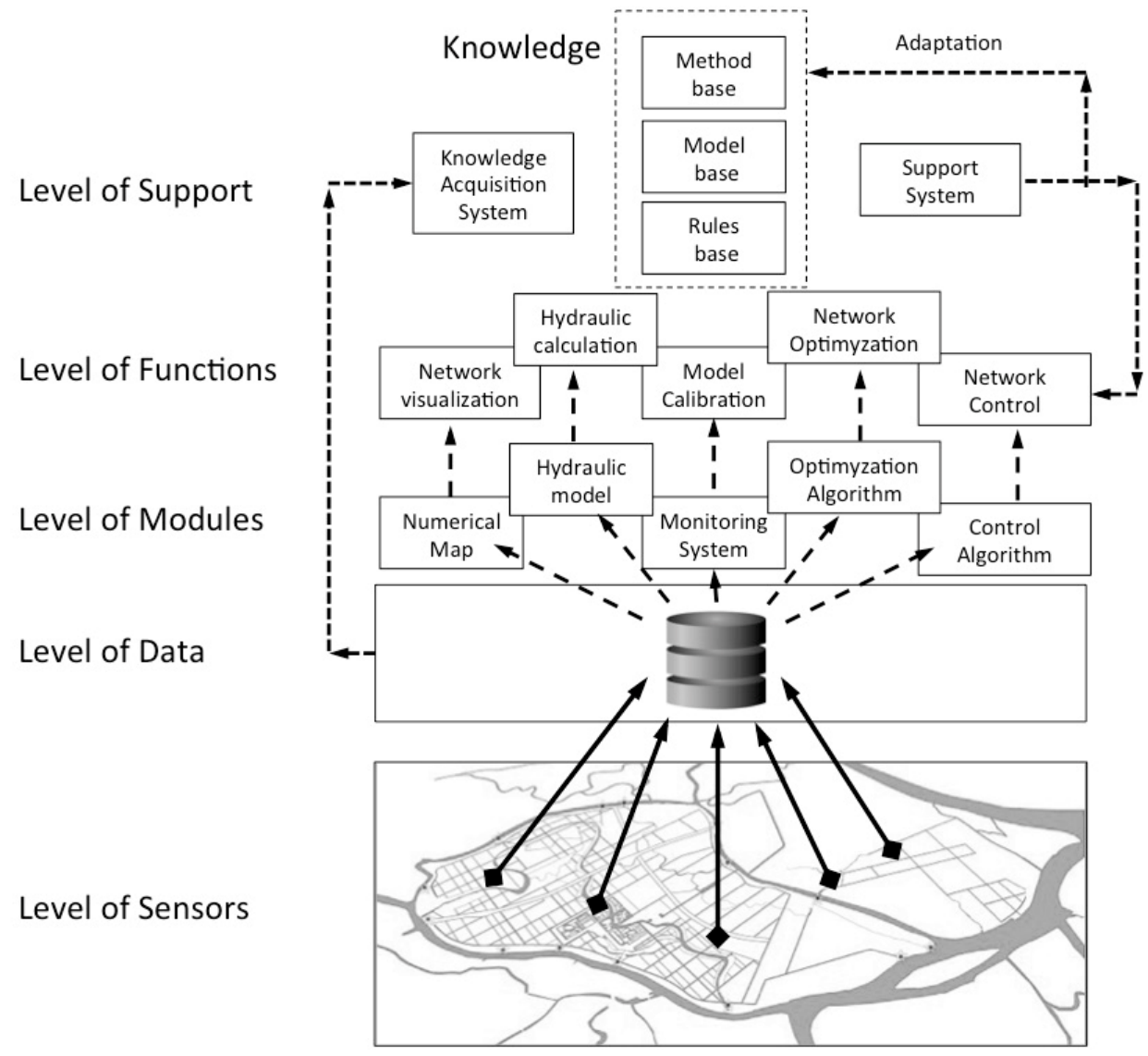

Figure 1. Decision tree of a Water Supply System (WSS).

The first effect of climate change on water systems is represented by the problem of water supply in many arid and semi-arid areas. The water demand can be completed at the local scale by unconventional water sources, as by desalination plants, or by advanced treatment plants. The economic viability of these solutions should be assessed performing a complete evaluation of the water production costs and of the water supply costs, including the opportunities of energy recovery in the new supply system [2,3]. From the perspective of an industrial management of the water system accurate water balances are requested from the regional to the local scale. New measurement technologies and larger system connectivity are improving the knowledge of the network, including the existing rank cross-correlations between users and at all temporal lags. New water demand models start to be developed based on this interesting big data series.

The topic that has been more largely treated in literature is the reduction of water leakage in pressurized water systems, representing the more efficient form of saving of the natural resources used in the system. This interest comes out from the large amount of water dispersed in the soil as an effect of pipe aging and other factors, as soil characteristics, pressure levels, traffic loads, etc. Statistics in Europe, referred to years 2012-2015, show that the amount of leakage is much more variable from one country to another, with a mean value of $23 \%$, Figure 2 [4]. Therefore, a large number of studies were addressed to obtain a characterization of water losses to set up a number of strategies for reducing the amount of leakage and to create numerical models for the dynamic control of the network. A literature review including each of these aspects can be found in [5,6] and [7-9], respectively. Product innovation is in general connected to the equipment for the location of the water losses in the network, based on water balances or on local measurements. A better knowledge of the flow distribution allows for a more detailed characterization of the user demand pattern, then increasing the model performance $[10,11]$. 


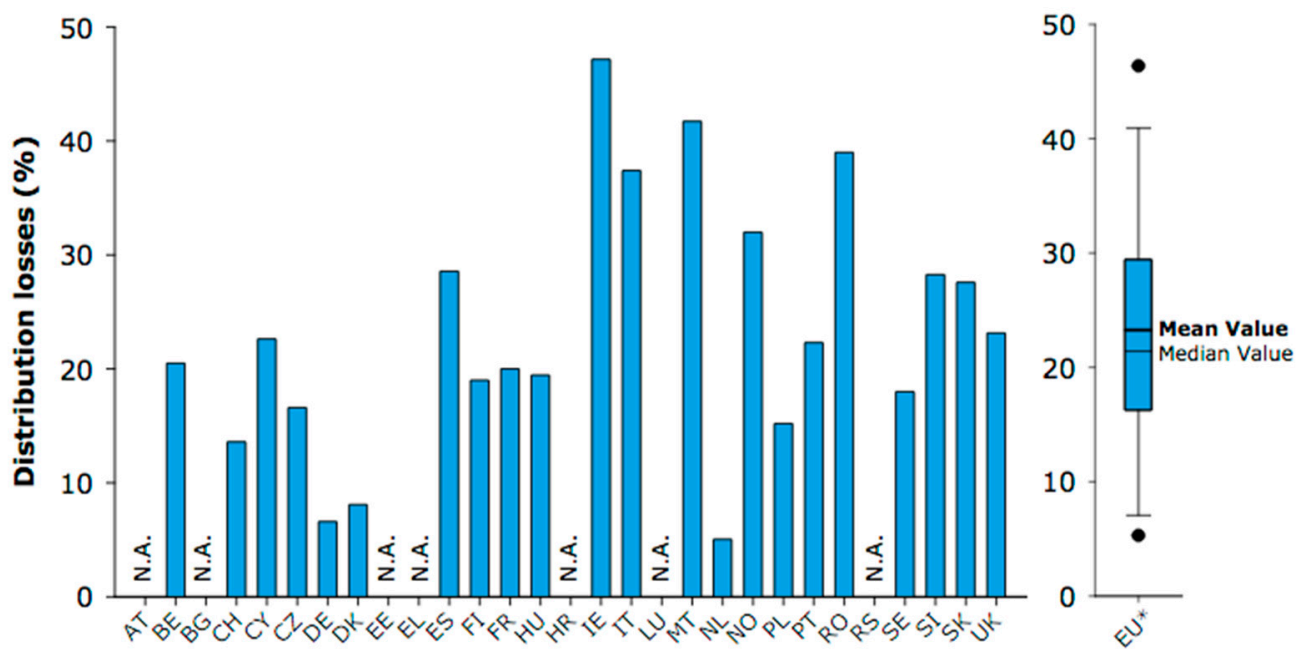

Figure 2. Water distribution losses in EC countries in the 2012-2015 period [4].

Two important strategies that are commonly used nowadays for leakage control are the creation of District Metered Areas (DMAs) in order to balance the water pressures and to make accurate resources balance, and the pressure reduction strategy, where the pressures in the network are reduced by Pressure Reducing Valves (PRVs) to minimize the water leakage. A research topic developed in the last decade is represented by the energy recovery in the dissipation nodes by Energy Production Devices (EPD). The assessment of EPDs performance is a frequent study topic and it is essential for the design of a micro and pico hydro power plant. The optimal location of EPDs and valves in the network is a complex problem to face with advanced numerical models. The most common EPDs are represented by the use of commercial Pumps As Turbines (PATs). A complete theory for PATs design and control in water supply networks has already been developed [12], including a detailed cost analysis [13], and a number of plants have been already installed $[6,12]$.

The problem of system control is also important in free surface conditions. An interesting research topic is represented by the control of gates in channels or in rivers in order to reduce the amount of water wasted, due to evaporation, leakage, and lack of control. Different control strategies can be considered, and the flow behavior can be simulated based on the Saint Venant equations.

This Special Issue comprises papers focused on the most important issues related to the application of innovative technologies for active control and energy efficiency in water supply systems, such as:

- Definition of dependencies and patterns in the big data analysis to be considered in a proactive multilevel historian application for water networks [14]

- Methodology for historian analysis of malfunctions in sewer networks as a support tool for the management authorities [15]

- Estimates of nodal demands for numerical simulation of water distribution networks [16]

- Assessment of the interaction between head and leak flow in innovative materials for pressurized hydraulic systems [17]

- Performance of EPDs for pico and micro hydropower in water distribution networks [18-20]

- Existing and emerging desalination technologies, their economic and environmental benefit, their potential application in arid zones [21]

- Application of new technologies for wastewater pumping with large environmental benefit [22,23]

- Application of automatic control to irrigation canals for improving the efficiency of water delivery $[24,25]$

Based on these contributions, this editorial will be organized in three macro-sections. Section 2.1 will consider the papers on big data analysis. Section 2.2 will be focused on the performance of EPDs 
for energy recovery in the water networks. Section 2.3 will present the contributions on the application of industrial technologies and control algorithms

\section{Contributed Papers}

\subsection{Big Data Analysis}

The conceptual view of a historian's application as conceived in an Industry 4.0 framework is described by [14]. A multilevel structure increases the potentialities of the big data analysis (Figure 3). The Level 1 algorithms are conceived to identify complex relationships and dependencies between technical system characteristics. Level 2 algorithms predict the future evolution of measured characteristics in order to make adjustments to the technical system. Level 3 algorithms are responsible for deciding how to influence the technical system in order to meet a defined objective. These algorithms are based on two distinct inputs: the predicted future evolution of the technical system, and a set of objectives provided by a technical system manager. Obviously, the proposed historian's architecture is proactive because it consists of a repetitive loop, whereby the evolution of the technical system is recorded, analyzed, and predicted, and then technical system evolution is altered from the prediction in order to achieve predefined goals. The objectives can be changed along the way, based on newly recorded data.

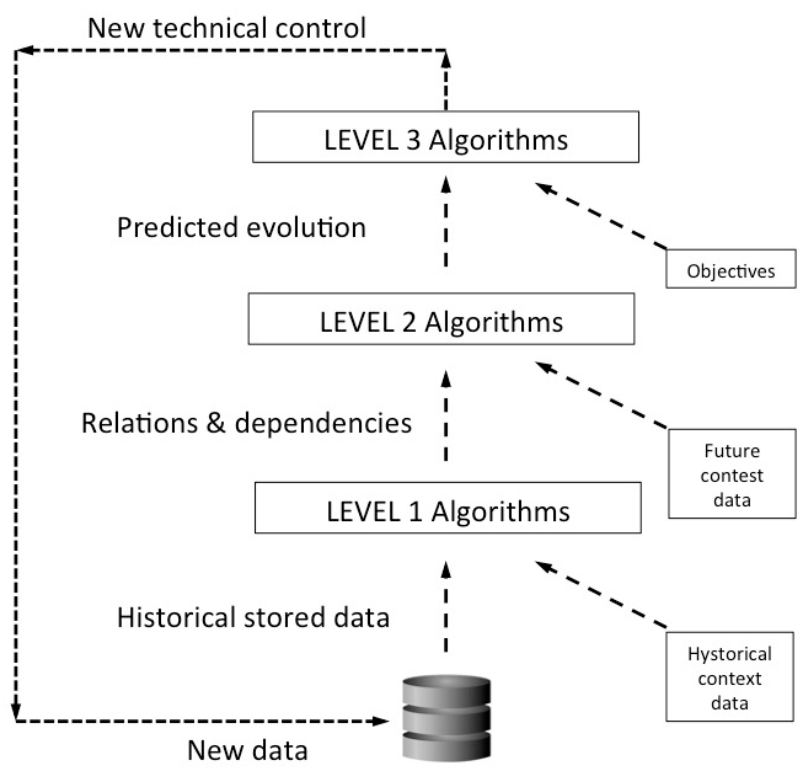

Figure 3. Reference proactive architecture for a network modeling and control based on historical data.

This methodology can be applied to all sectors of WSS, and an example was performed to a water treatment facility that receives water from several water wells and sends the treated water to the distribution network using a pumping station and reservoirs, with the purpose of reducing operational costs. Several dependencies were identified between measured characteristics, such as adsorbed energy, turbidity, equipment functioning, etc. Following the data dependency identification, quality priority indicators were associated to each water well, and total priority indicators and flow setpoints for local control loops were determined. Then, a proactive change of the local flow setpoints in each well was decided, with a noninvasively change of the local system behavior. A final $9 \%$ energy efficiency improvement was demonstrated.

Level 1 Algorithms are generated on the basis of measured characteristic values. Despite the potential computerized framework of a big data analysis, a preliminary definition of the relevant characteristics of the system is generally required. Then, an improvement of the frequency and accuracy of the measurements will be suggested, starting from the first stage to the subsequent 
stage of this proactive management. The study on the malfunctions of sewer networks of Southern Italy provides this kind of starting information [15]. Based on a very simple database, that was traditionally drafted by Italian water management authorities, containing a brief qualitative description of the situation, including the reasons for the call, nature of disservice, location, possible causes, and the following intervention, an analysis of the recorded interventions was performed. Type and frequency of the malfunction were put in relation with the characteristics of the sewer pipelines, of the location in the network, of the kind of urban aggregate. In general, the correlations are very complex for the presence of many hidden factors. As an example, we can observe from the distribution of the interventions per kilometer due to breakage vs. pipe material that stoneware pipelines have the highest vulnerability for the provinces of Taranto, Lecce, and Brindisi, followed by reinforced concrete pipelines in Brindisi and Taranto provinces, and steel pipelines in the Lecce province. A dependency of the number of interventions per kilometer vs. the number of inhabitants was also revealed, Figure 4.
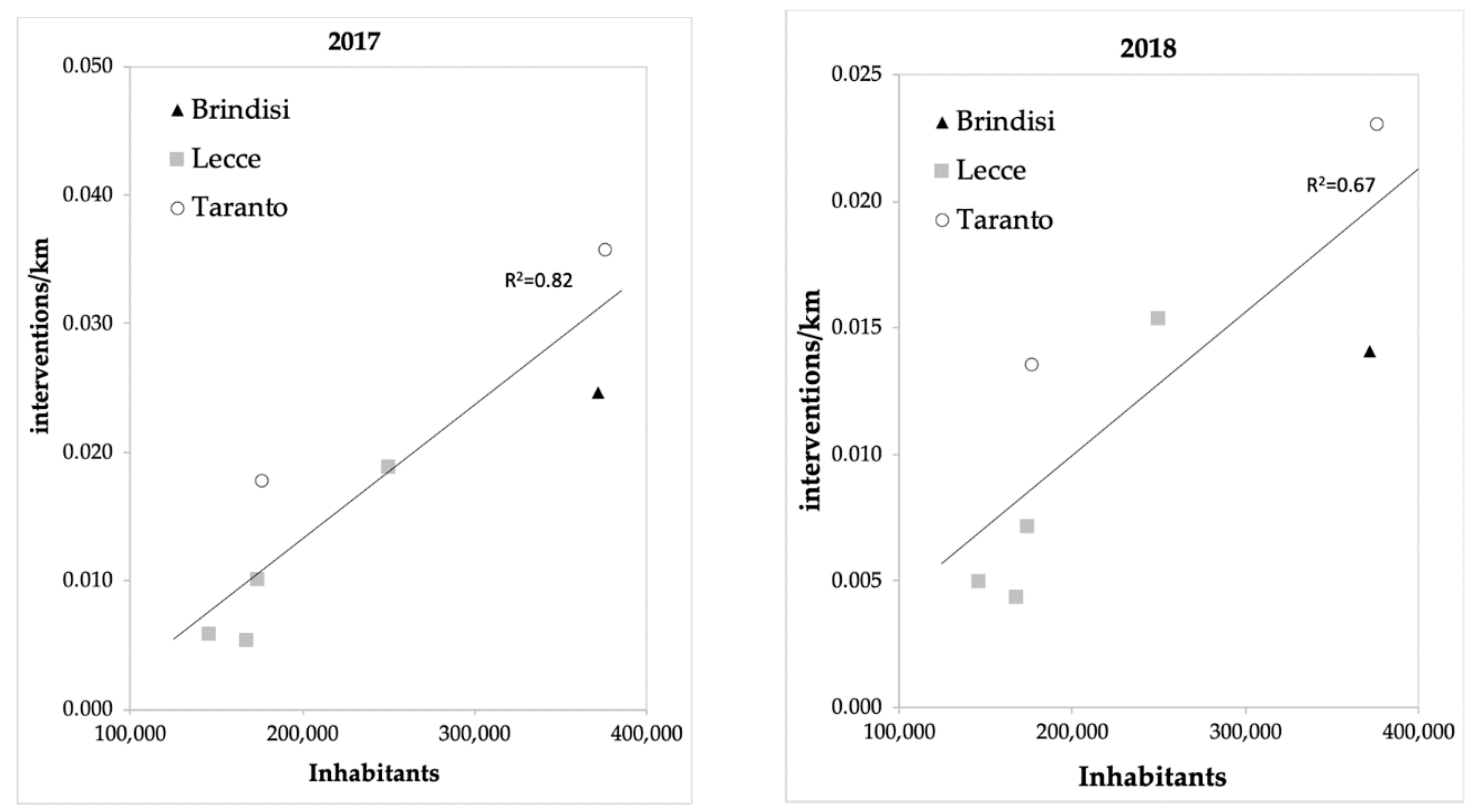

Figure 4. Interventions per kilometer of wastewater pipelines vs. inhabitants [15].

The generation of a water-demand time series at both single user and nodal scales is a typical problem for network simulation programs. Big data coming from the hourly consumption data of a smart water network located in a suburban area of Naples (Italy) were considered in [16]. In Figure 5, the measured daily demand time series are plotted for a small water district (1000 users) and for a large water district (1000 users). The distributions were analyzed according with two different approaches suggested in literature, namely the top-down approach and the bottom-up approach. The bottom-up procedure was found to perform significantly better than the top-down procedure in terms of rank-cross correlations at a fine scale. However, the top-down procedure showed a better performance in terms of skewness and rank cross-correlation when the aggregated demands were considered. Both procedures generate results perfectly comparable with the measured distribution at an aggregate scale, Figure 6. 

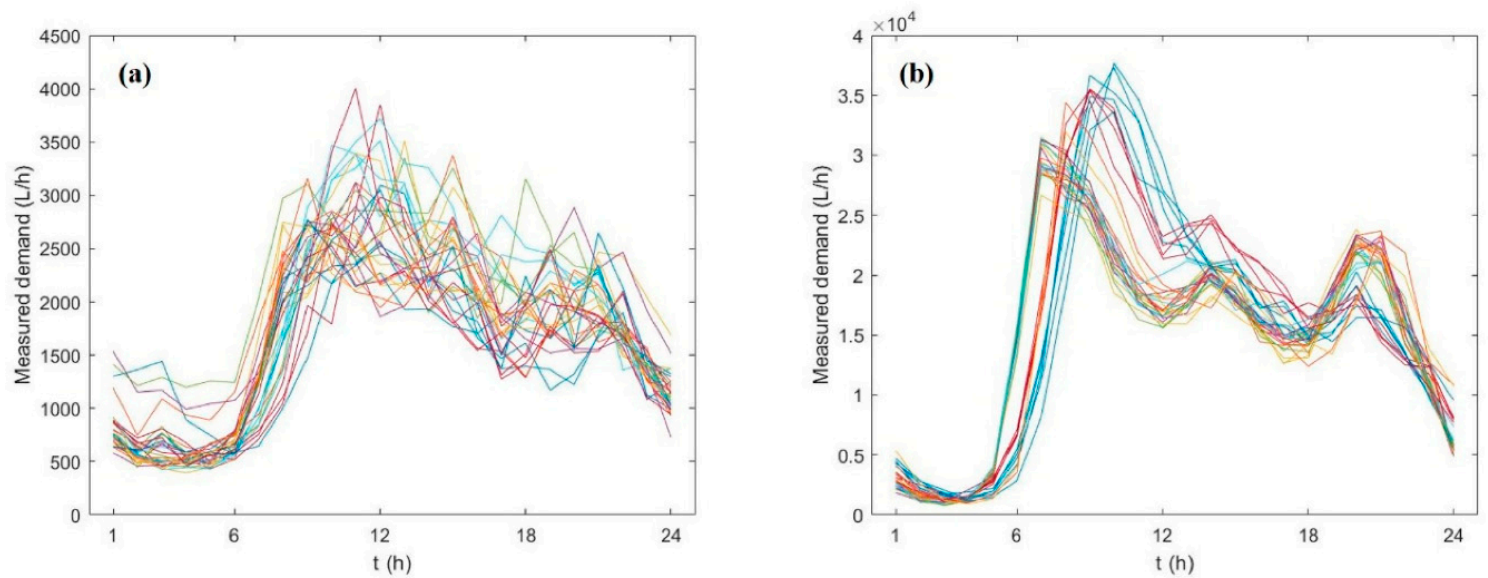

Figure 5. Patterns of aggregated measured hourly demand for 31 days for Case study 1 (a) and Case study 2 (b), respectively [16].
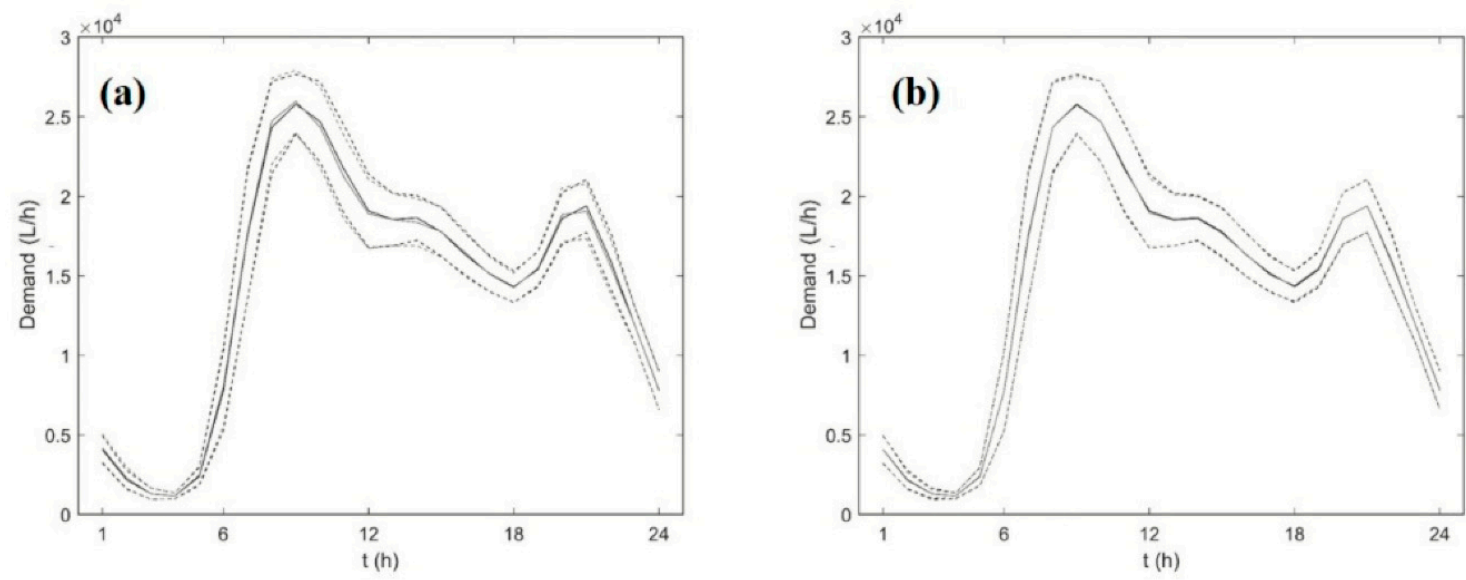

Figure 6. Daily temporal patterns of both mean $\mu$ (continuous lines) and intervals $\mu \pm 0.5 \sigma$ (dotted lines) for measured (black lines) and generated (grey lines) aggregated demands: the generated demands were obtained applying the top-down approach (a) and the bottom-up approach (b), respectively [16].

Another typical problem for network simulation is represented from the hydraulic characterization of the real losses. These kinds of studies are generally performed by physical experiments. As a result, the relationship between the leak outflow and the hydraulic head and the geometric features of the hole and the mechanical characteristics of the pipe, are obtained. Nowadays, the technical innovation is represented by the possibility of modeling numerically the flow field at the orifice [17]. Experiments were performed on a drilled PVC-A (Polyvinyl Chloride-Alloy), presenting a rectangular orifice of $20 \times 3 \mathrm{~mm}$, realized in the bottom side of the pipe, oriented transversally to the flow direction. A Computational Fluid Dynamics (CFD) model was then implemented and calibrated with experimental results, to different geometric configurations of the orifice, with the aim of assessing the dependence of the orifice geometry and orientation on the calibration of leakage law parameters. As an example of the work potentiality, the velocity fields obtained numerically are plotted in Figure 7, for different values of the pipe flow rate. 


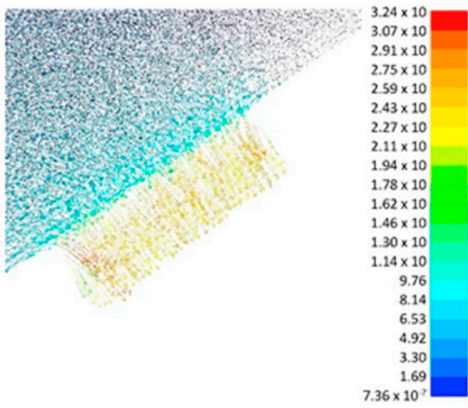

(a)

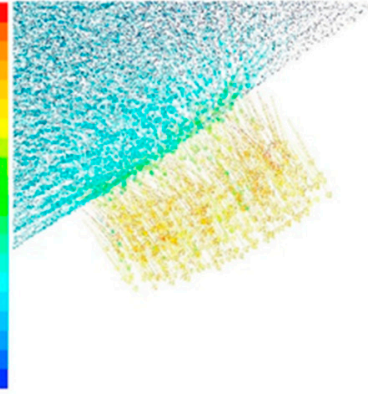

(b)

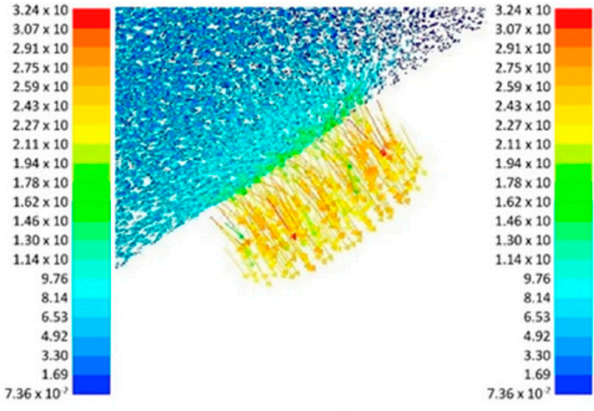

(c)

Figure 7. Velocity field for longitudinal orifice at $P=5.0$ bar and Qin $=(\mathbf{a}) 10 \mathrm{~L} / \mathrm{s},(\mathbf{b}) 20 \mathrm{~L} / \mathrm{s},(\mathbf{c}) 30 \mathrm{~L} / \mathrm{s}$ [17].

\subsection{Technologies for Micro to Pico Hydropower}

EPDs for energy recovery in WSS can be based on different principles, depending on the flow conditions and on the amount of energy that is required locally. In many cases, traditional turbines can be used. In particular, Francis turbines are generally operated in the large water transmission lines, where stable conditions of flow rate and head drop are observed. Pelton turbines are also in use to recover the residual energy at the end of the pipelines when free discharge conditions are present. In water distribution these devices are not suitable due to the observed daily variability of the flow rate and head drop. Another problem for hydropower exploitation in water distribution is represented by the limited power dissipated in the pressure reduction valves (Figure 8a) [18]. As a consequence, in presence of large costs for the EPD, the control system and housing are not viable. In Figure 8b, the annual income of hydro power plants is plotted as a function of the installed power, for two unit costs, and ten years of investment, representing the best and the worst scenario. A five years payback period can be obtained for a plant size between 3 and $20 \mathrm{~kW}$ only in presence of the only electro-mechanical costs. Hence, the research is now focused on low cost, reliable EPDs to be installed with limited installation and maintenance costs.

(a)

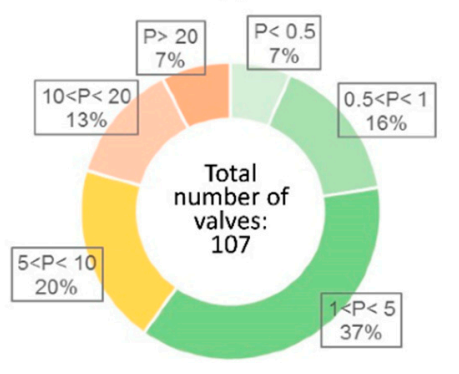

Power classes:

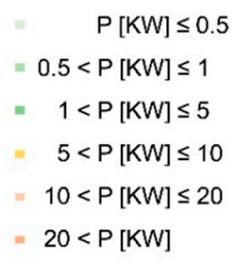

(b)

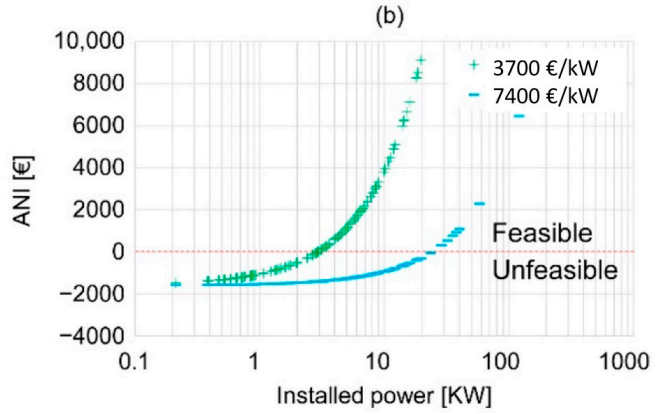

Figure 8. Real data on the dissipated power in Pressure Reducing Valves (PRVs) [18] showing (a) the numbers of valve for class of dissipated power, and (b) the Annual Net Income (ANI) for ten years investment in case of specific installation cost of $3700 € / \mathrm{kW}$ and $7400 € / \mathrm{kW}$.

In many situations, only a small amount of energy is necessary in the dissipation node, in order to create a stand-alone monitoring node with remote control ability. A smart solution, Figure 9 is represented by the Green Valve System (GVS), replacing in line an existing pressure reducing valve, allowing a perfect energy supply and connection to a control and metering station in a node of a WSS. 


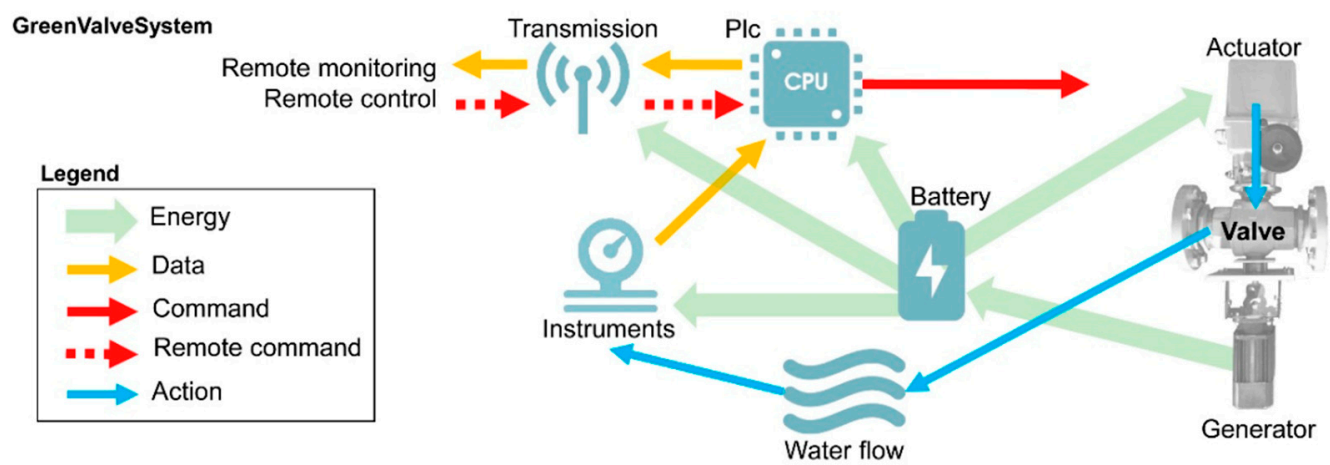

Figure 9. Green Valve System [18].

A pump operated as turbines (PATs) is probably the most promising EPD for WSS, due to the reduced costs in comparison with classic turbines, to the low maintenance costs and to the large industrial production. The major obstacle that inhibits the practical application of PATs in actual projects is the lack of performance data (best efficiency point data, characteristic curves). The availability of relationships between the pump and turbine mode performance data could remove this obstacle, at least in preliminary design stages. In the past, a number of models were published operating this kind of prediction (see [12] for a literature review), but the performance is frequently poor. These models were calibrated for large, single stage, centrifugal PATs and the extrapolation to smaller units of a different type is critical. This problem can be overcome by introducing a correction function or by recalibrating an existing model. The first approach was used for Multistage Submersed Pumps [26], while the second is proposed by [19] with an extension of Derakhshan and Nourbakhsh model [27]. The new calibration has been performed using experimental data on 20 ESOB (End Suction Own Bearing) devices, 7 MSV (Multi-Stage Vertical), 6 MSH (Multi-Stage Horizontal) and one MSS (Multi-Stage Submersible) industrial pumps, collected within the Reduction Energy Dependency in Atlantic area Water Networks (REDAWN) Interreg Atlantic Area project. In Figure 10, the results of the new model are compared to MSV data and to the Derakhshan and Nourbakhsh model.
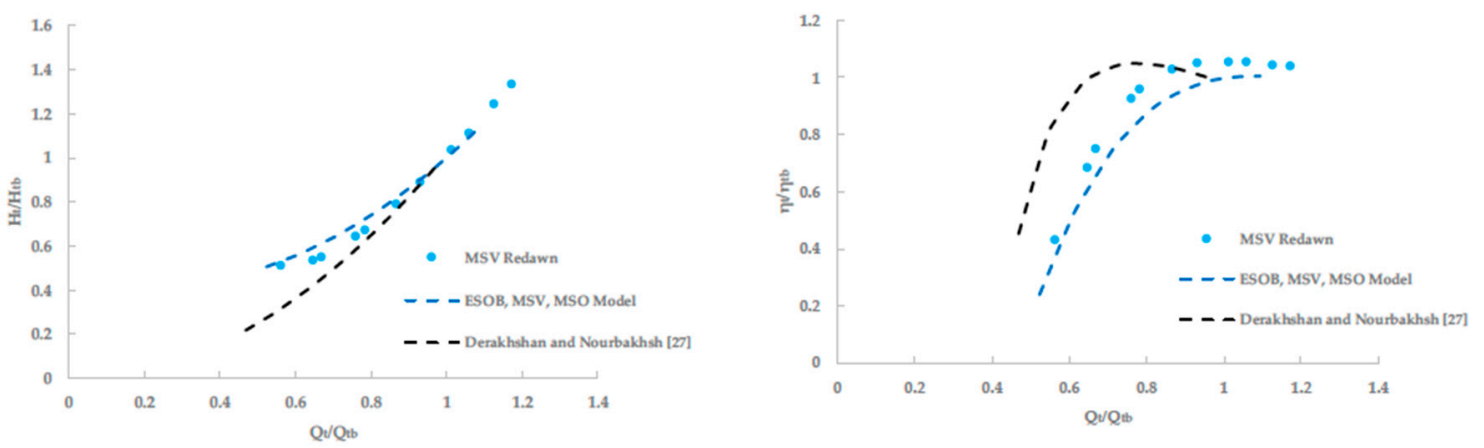

Figure 10. Experimental and theoretical performance curves for MSV pumps used in inverse mode.

New and reliable data of PAT are useful for the design of future micro hydro power plants. An interesting procedure for the selection is suggested in [20], where the lack of reliable data from the pump manufacturers is overcome by direct pump testing in inverse mode on a new experimental rig, Figure 11. Based on the daily distribution of flow rate and pressure head in the dissipation node, the choice of the best PAT speed can be performed by specific tests, and the daily distribution of pressure drop can be exactly evaluated, Figure 12. 


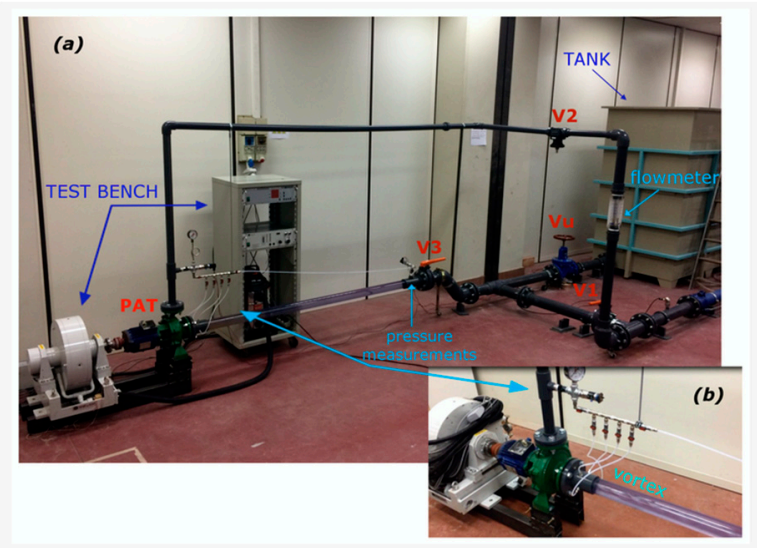

Figure 11. Test setup: (a) main elements of the supply system; and (b) vortex generation at the Pumps As Turbines (PAT) outlet [20].
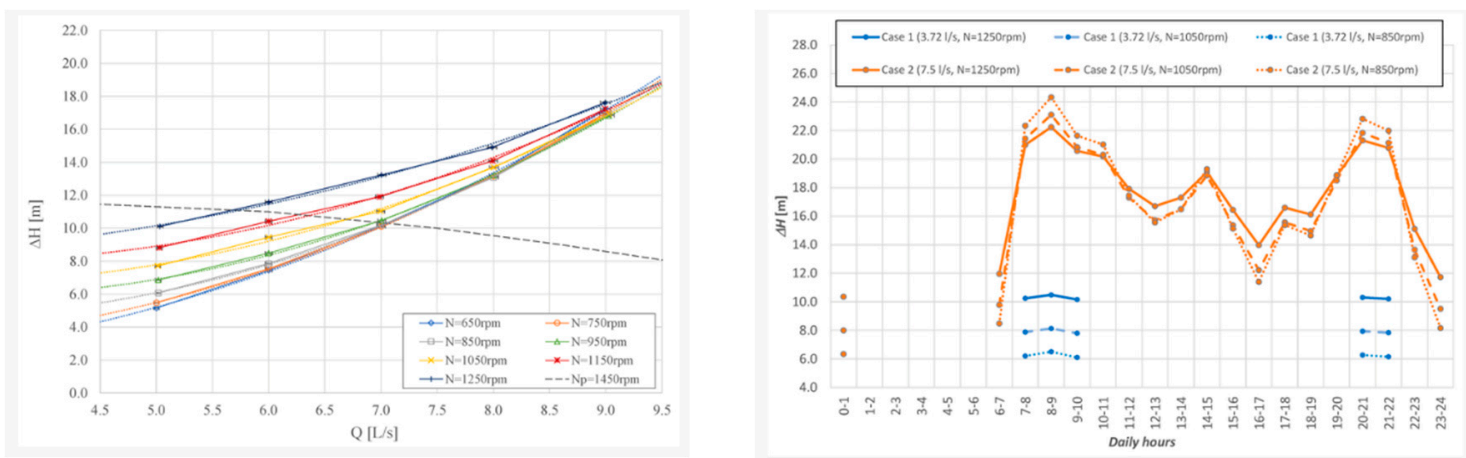

Figure 12. Measured PAT curves and daily distribution of the head drop for variable impeller speed [20].

\subsection{Industrial Technologies and Control Algorithms}

The last series of contributions refer to industrial application of existing technologies. A correct analysis of the potentiality of any innovation is fundamental to obtain a good exploitation for the technology. In the presence of mature technologies, this analysis can be performed with high accuracy, involving also the environmental benefit of the design solution. A technology that is exhibiting large advancement is the desalination [21]. In the case of the Saudi Arabia sites of Figure 13, great savings in terms of water cost and impressive reductions in terms of $\mathrm{CO}_{2}$ emission will be obtained by upgrading the existing design plans by introducing the most advanced technology of water production and a more rational scheme of hydraulic supply (Table 1).

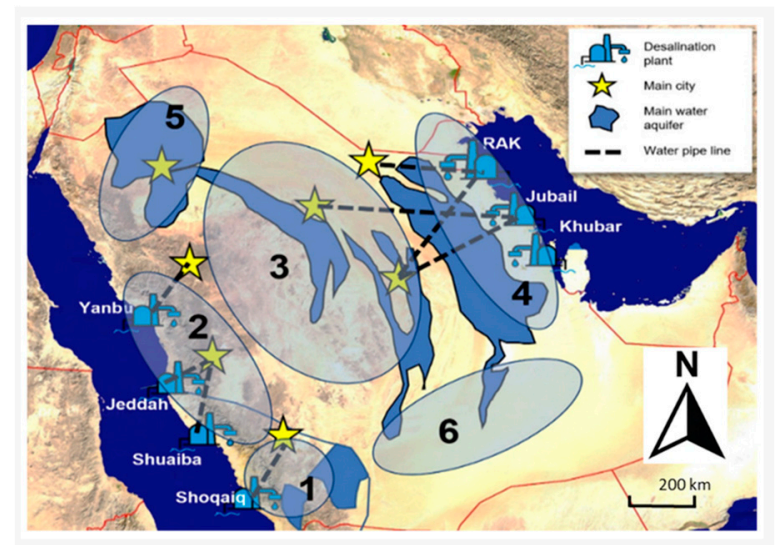

Figure 13. Water resources and main demand zones in Saudi Arabia [21]. 
Table 1. Impact of new technologies and decentralization on energy consumption and $\mathrm{CO}_{2}$ emissions [21].

\begin{tabular}{|c|c|c|c|c|c|c|c|}
\hline \multirow[b]{2}{*}{ City } & \multirow[b]{2}{*}{ Plant } & \multirow[b]{2}{*}{$\begin{array}{l}\text { Length }(\mathbf{k m}) \\
\text { Height (m) }\end{array}$} & \multirow[b]{2}{*}{$\begin{array}{c}\text { Water Flow } \\
\left(M^{3} / \text { day }\right)\end{array}$} & \multicolumn{2}{|c|}{$\begin{array}{c}\text { Existing Plan } \\
\text { Transmission Pipeline + Current Plants }\end{array}$} & \multicolumn{2}{|c|}{$\begin{array}{c}\text { Proposed Plan } \\
\text { Decentralized-ADD without Pipelin }\end{array}$} \\
\hline & & & & $\begin{array}{c}\text { Water-Transmission } \\
\text { Energy Cost } \\
\text { (MUSD/year) }\end{array}$ & $\begin{array}{c}\text { Emissions } \\
\text { (tons } \mathrm{CO}_{2} / \text { year) }\end{array}$ & $\begin{array}{l}\text { Water-Production } \\
\text { Energy Cost } \\
\text { (MUSD/year) }\end{array}$ & $\begin{array}{c}\text { Emissions } \\
\text { (tons } \mathrm{CO}_{2} / \text { year) }\end{array}$ \\
\hline Makkah & Shoaibah & $\begin{array}{c}90 \\
240\end{array}$ & 550,000 & 82.9 & 653,943 & 12.8 & 101,671 \\
\hline Madinah & Yanbu & $\begin{array}{l}162 \\
631\end{array}$ & 450,000 & 99.5 & 784,530 & 10.5 & 83,186 \\
\hline Abha & Shoqaiq & $\begin{array}{c}105 \\
2084\end{array}$ & 100,000 & 25.1 & 198,165 & 2.3 & 18,485 \\
\hline Riyadh & Jubail & $\begin{array}{l}400 \\
612\end{array}$ & 950,000 & 290.6 & $2,291,034$ & 22.2 & 175,615 \\
\hline
\end{tabular}


Wastewater pumping and treatment is another sector where promising environmental benefits could be pursued by the introduction of new technologies and control systems. One of the main limitations in the exploitation of PAT technology is the necessity of a local use of the recovered energy. A possibility is represented by the use of turbo-pumps, with a direct coupling of a PAT and a pump [22]. The theory was already discussed for freshwater application but has been extended to the energy transfer from the freshwater to the wastewater network (Figure 14). The viability of the new technology is expressed by an economic comparison with a more conventional design solution presenting a hydro power plant in the dissipation node of the freshwater network and a wastewater pumping system, working in on/off mode. A positive difference in the Net Present Value (NPV) between the two solutions expresses an economic advantage of the turbo-pump technology. The benefit of the new technology is larger on the small period and is strongly affected by the runoff coefficient of the drainage network (Figure 15).

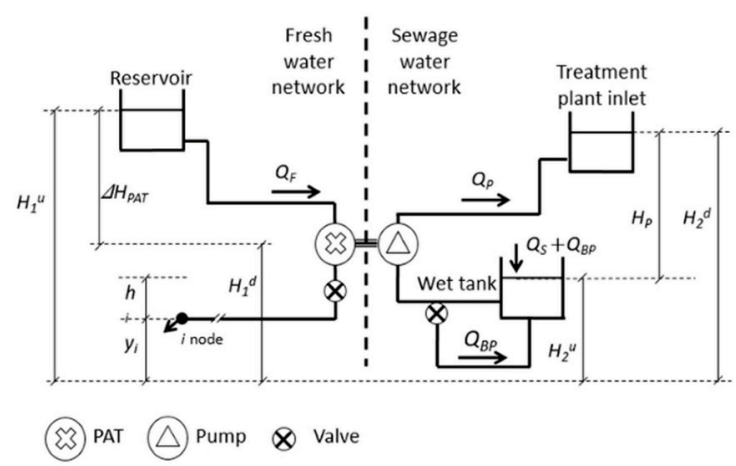

Figure 14. Hydraulic scheme of a freshwater turbine-wastewater pump system [22].

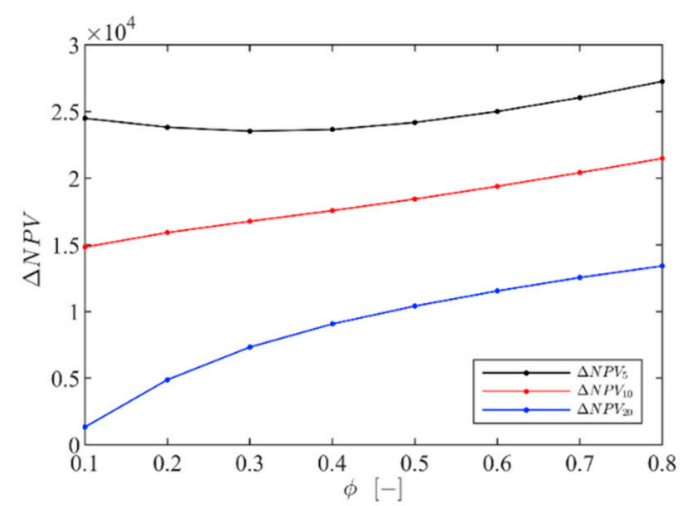

Figure 15. Difference of Net Present Value (NPV) vs the runoff coefficient $(\varphi)$, for different time periods $(5,10$, and 20 years) [22].

According to the basics of the eco-design, a pumping group, made by a pump, motor, speed driver, and regulation devices, working with variable speed is considered the best opportunity for the reduction of energy use in water systems. A pump scheduling optimization consists of finding, for each time step, the rotational speed of the group in order to minimize the total energy adsorbed during the day. Variable flow conditions have not been implemented yet for wastewater pumps operating in small wet tanks for a number of reasons: the optimization problem is more complicate including on/off scheduling and rotational speed value; the presence of sediments in the water might change the performance of the group with the pump age; there are issues concerning the pump clogging when the flow rate is reduced. The first two issues have been treated in [23]. Laboratory experiments have been performed on a chopper pump affected by progressive wear, obtaining accurate performance curves (Figure 16). Then a pump scheduling optimization problem was solved for a real outflow 
measured in the drainage network of Napoli (Italy), for different plant curves (Figure 17a). The global efficiency of the group working in variable flow conditions has been compared with the efficiency of the group working in constant flow conditions (on/off) (Figure 17b). The mechanical wear was found to affect the potential benefit of the pump speed control. In particular, an accurate maintenance program is necessary in pumping system with large geodetic head in order an economic advantage from the use of a variable speed control.

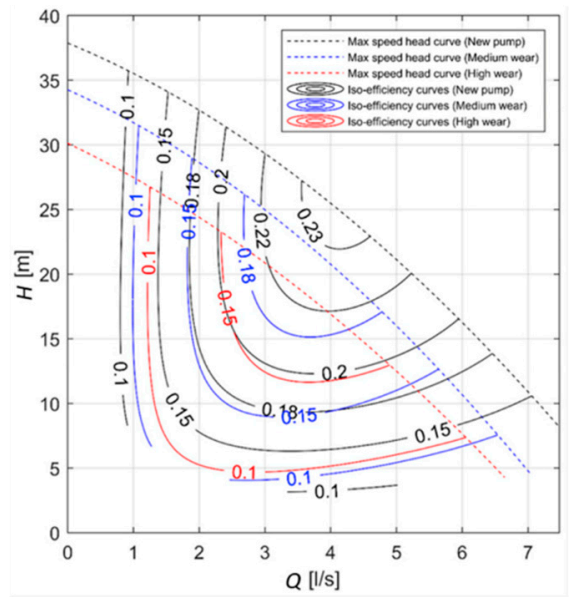

Figure 16. Comparison of characteristic and efficiency curves for different stages of wear [23].

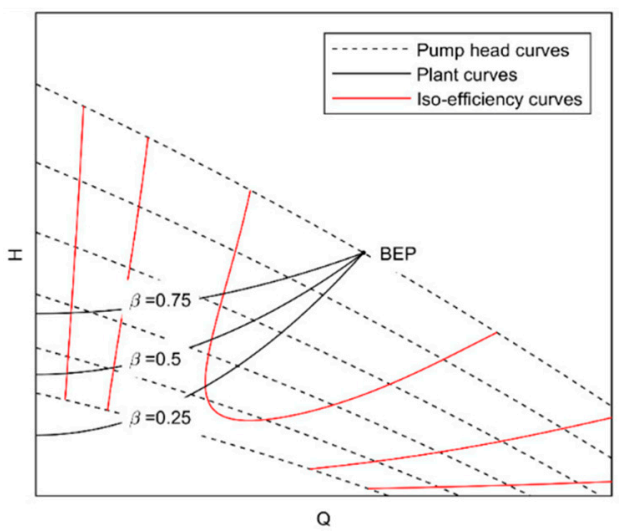

(a)

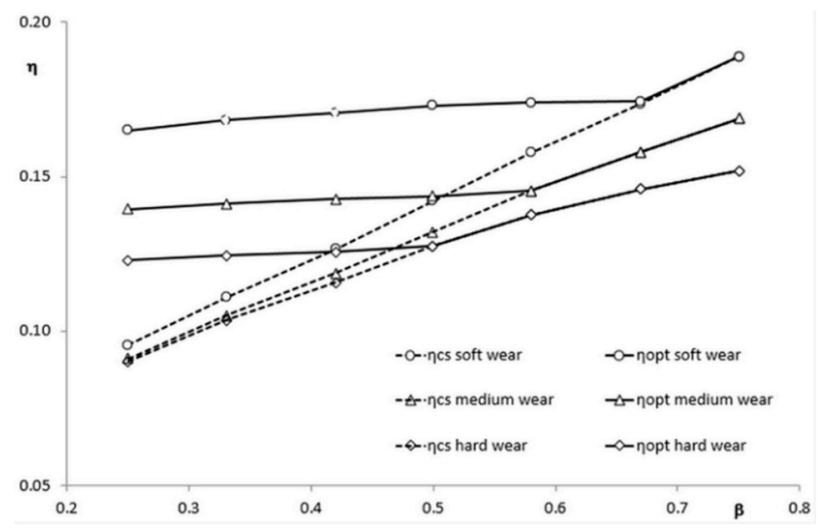

(b)

Figure 17. (a) Simulated plant head curve; (b) global plant efficiency for different stages of wear.

The automatic control of the water level in an irrigation canal by automatic regulation of intermediate gates was the last topic treated in the Special Issue. Canal automation has recently evolved to the point where most new canal designs and canal modernization projects include a large level of automation. In the first paper [24], a numerical result to the problem of gate regulation was proposed on three scenarios on a channel presenting six adjacent pools, each of one supplying a different irrigation network (Figure 18). Despite the simplicity of the classic Saint Venant equations describing the physical process, the solution of the gate control optimization required a powerful Model Predictive Control (MPC). MPC is a control strategy that explicitly uses a simplified process model of the real system to obtain control actions by minimizing an objective function. 


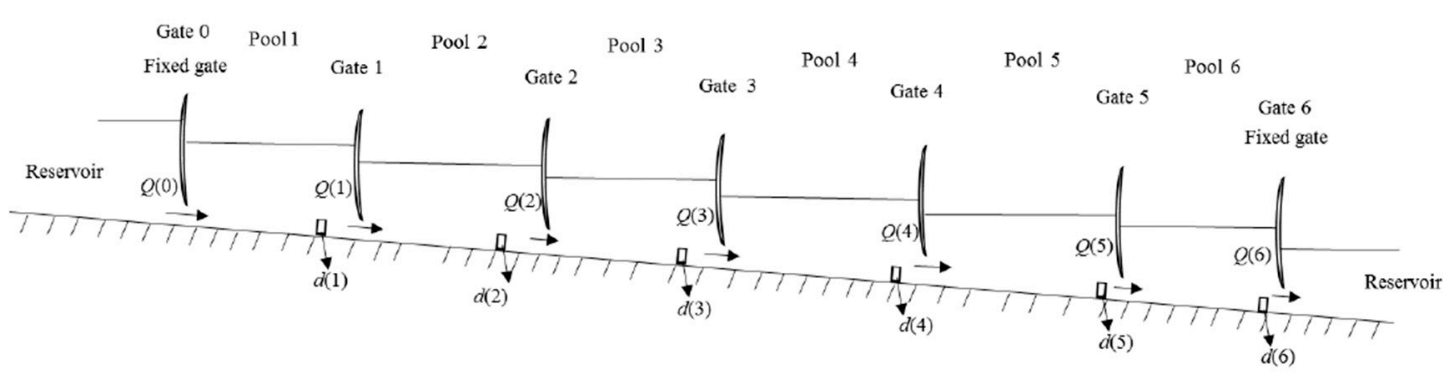

Figure 18. Layout of the studied canal system [24].

The control strategy was applied in [25] to the largest open canal water transfer project in China, the Middle Route Project (MRP) for South-to-North Water Transfer (Figure 19). Thirteen pools were considered in the model, for a total length of the canal of $227.3 \mathrm{~km}$. The results of the simulation demonstrated that the MPC system deals with both known and unknown disturbances, albeit with a degree of resonance in some short pools. However, the calculation times for the whole MRP network are at present too long to satisfy the requirements of real-time control. Therefore, from the perspective of shortening the calculation time of the control system, it is important to set up some reservoirs to divide the MRP into several separate canal systems.

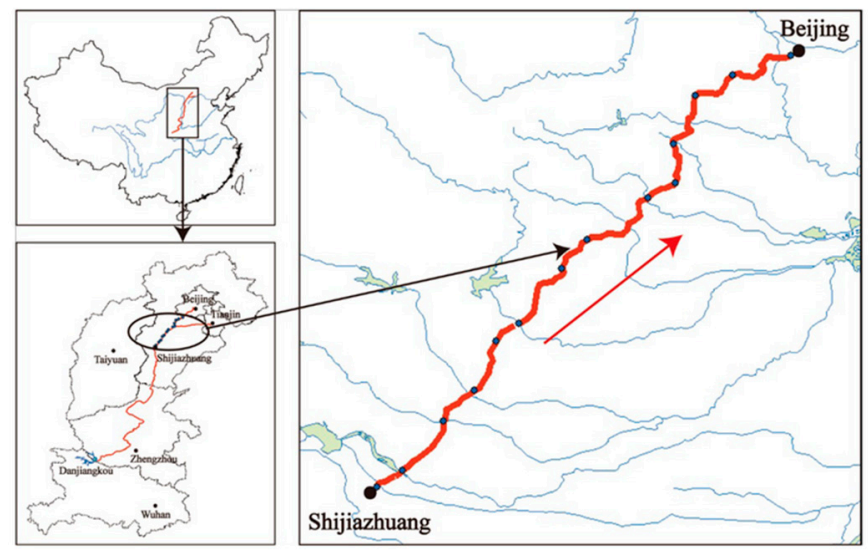

Figure 19. Middle Route Project (MRP) for South-to-North Water Transfer [25].

\section{Conclusions}

Product innovation is the real key for improving the management of Water Supply Systems, increasing the global efficiency of the water transfer and leading to the application of circular economy models. In the framework of the water-energy-food nexus, the ultimate goal is to distribute water to the end users with the optimal energy and quality values. For the complexity of the WSS supply and network geometry, for the variability of the ground altimetry, and for the daily variation of the water demand, an optimal distribution is possible only by an active control of all components of the network, i.e., pumps, gates, valves, meters, etc.

All products and control algorithms might be distributed in a structured decision tree, and all data acquired in the network might undergo a multi-level proactive analysis for simulating the future states of the system, supporting the WSS management in their decision. In this view, the contributions to this Special Issue are strongly homogeneous, watching different WSS aspects, but with the same perspective of increasing the active control and the energy efficiency of the network. The readers will find real innovation, but all Authors were aware of the importance of the transferability of their technologies or the modeling approach to the real WSS management. 
The water sector, generally considered a very traditional sector, will be completely changed by the new paradigms of Industry 4.0, Big Data and the Internet of Things (IoT). We hope that this volume will open a window on this next future change.

Author Contributions: A.C. conceived and led the development of this Special Issue and this paper; M.G. and S.M. contributed substantially to the writing. All authors have read and agreed to the published version of the manuscript.

Funding: This research received no external funding

Acknowledgments: The authors of this paper, who served as guest editors of this Special Issue, wish to thank the journal editors, all authors submitting papers to this Special Issue, and the many referees who contributed to paper revision and improvement of all published papers.

Conflicts of Interest: The authors declare no conflict of interest.

\section{Acronyms:}

$\begin{array}{ll}\text { CFD } & \text { Computational Fluid Dynamics } \\ \text { DMA } & \text { District Metered Area } \\ \text { EPD } & \text { Energy Production Device } \\ \text { ESOB } & \text { End Suction Own Bearing } \\ \text { GVS } & \text { GreenValve System } \\ \text { IoT } & \text { Internet of Things } \\ \text { MEI } & \text { Minimum Efficiency Index } \\ \text { MHP } & \text { Micro-hydropower } \\ \text { MPC } & \text { Model Predictive Control } \\ \text { MSV } & \text { Multi-Stage Vertical } \\ \text { MSH } & \text { Multi-Stage Horizontal } \\ \text { MSS } & \text { Multi-Stage Submersible } \\ \text { NPV } & \text { Net Present Value } \\ \text { PAT } & \text { Pump as turbine } \\ \text { PRV } & \text { Pressure reducing valve } \\ \text { PSH } & \text { Pumped-storage hydropower } \\ \text { WDN } & \text { Water distribution network } \\ \text { WSS } & \text { Water supply system }\end{array}$

\section{References}

1. Rojek, I. Models for Better Environmental Intelligent Management within the Water Supply Systems. Water Resour. Manag. 2014, 28, 3875. [CrossRef]

2. Carravetta, A.; Fecarotta, O.; Golia, U.M.; La Rocca, M.; Martino, R.; Padulano, R.; Tucciarelli, T. Optimization of Osmotic Desalination Plants for Water Supply Networks. Water Resour. Manag. 2016, 30, 3965. [CrossRef]

3. Morani, M.C.; Carravetta, A.; Del Giudice, G.; McNabola, A.; Fecarotta, O. A comparison of energy recovery by pATs against direct variable speed pumping in water distribution networks. Fluids 2018, 3, 41. [CrossRef]

4. Europe's Water in Figures: An Overview of the European Drinking Water and Waste Water Sectors 2017 Edition. Available online: www.eureau.org/resources/publications/1460-eureau-data-report-2017-1/file (accessed on 20 November 2020).

5. Abd Rahman, N.; Muhammad, N.S.; Wan Mohtar, W.H.M. Evolution of research on water leakage control strategies: Where are we now? Urban Water J. 2018, 15, 812-826. [CrossRef]

6. Xu, Q.; Liu, R.; Chen, Q.; Li, R. Review on water leakage control in distribution networks and the associated environmental benefits. J. Environ. Sci. (China) 2014, 26, 955-961. [CrossRef]

7. Fontana, N.; Giugni, M.; Glielmo, L.; Marini, G.; Zollo, R. Real-time control of pressure for leakage reduction in water distribution network: Field experiments. J. Water Resour. Plan. Manag. 2018, 144, 04017096. [CrossRef]

8. Gupta, A.; Kulat, K.D. A Selective Literature Review on Leak Management Techniques for Water Distribution System. Water Resour. Manag. 2018, 32, 3247-3269. [CrossRef] 
9. Araujo, L.S.; Ramos, H.; Coelho, S.T. Pressure control for leakage minimisation in water distribution systems management. Water Resour. Manag. 2006, 20, 133-149. [CrossRef]

10. Fiorillo, D.; Galuppini, G.; Creaco, E.; De Paola, F.; Giugni, M. Identification of Influential User Locations for Smart Meter Installation to Reconstruct the Urban Demand Pattern. Water Resour. Manag. 2020, 146, 04020070.

11. Blokker, E.J.M. Stochastic Water Demand Modelling for A Better Understanding of Hydraulics in Water Distribution Networks; Water Management Academic Press: Delft, The Netherlands, 2010.

12. Carravetta, A.; Houreh, S.D.; Ramos, H.M. Pumps as Turbines: Fundamentals and Applications, 1st ed.; Springer: Cham, Switzerland, 2017.

13. Novara, D.; Carravetta, A.; McNabola, A.; Ramos, H.M. Cost Model for Pumps as Turbines in Run-of-River and In-Pipe Microhydropower Applications. J. Water Resour. Plan. Manag. 2019, 145, 04019012. [CrossRef]

14. Nicolae, A.; Korodi, A.; Silea, I. Identifying Data Dependencies as First Step to Obtain a Proactive Historian: Test Scenario in the Water Industry 4.0. Water 2019, 11, 1144. [CrossRef]

15. Balacco, G.; Iacobellis, V.; Portincasa, F.; Ragno, E.; Totaro, V.; Piccinni, A.F. Analysis of a Large Maintenance Journal of the Sewer Networks of Three Apulian Provinces in Southern Italy. Water 2020, 12, 1417. [CrossRef]

16. Ferraiuolo, R.; De Paola, F.; Fiorillo, D.; Caroppi, G.; Pugliese, F. Experimental and Numerical Assessment of Water Leakages in a PVC-A Pipe. Water 2020, 12, 1804. [CrossRef]

17. Fiorillo, D.; Creaco, E.; De Paola, F.; Giugni, M. Comparison of Bottom-Up and Top-Down Procedures for Water Demand Reconstruction. Water 2020, 12, 922. [CrossRef]

18. Fontanella, S.; Fecarotta, O.; Molino, B.; Cozzolino, L.; Della Morte, R. A Performance Prediction Model for Pumps as Turbines (PATs). Water 2020, 12, 1175. [CrossRef]

19. Ferrarese, G.; Malavasi, S. Perspectives of Water Distribution Networks with the GreenValve System. Water 2020, 12, 1579. [CrossRef]

20. Postacchini, M.; Darvini, G.; Finizio, F.; Pelagalli, L.; Soldini, L.; Di Giuseppe, E. Hydropower Generation Through Pump as Turbine: Experimental Study and Potential Application to Small-Scale WDN. Water 2020, 12, 958. [CrossRef]

21. Alnajdi, O.; Wu, Y.; Kaiser Calautit, J. Toward a Sustainable Decentralized Water Supply: Review of Adsorption Desorption Desalination (ADD) and Current Technologies: Saudi Arabia (SA) as a Case Study. Water 2020, 12, 1111. [CrossRef]

22. Morani, M.C.; Carravetta, A.; Fecarotta, O.; McNabola, A. Energy Transfer from the Freshwater to the Wastewater Network Using a PAT-Equipped Turbopump. Water 2020, 12, 38. [CrossRef]

23. Fecarotta, O.; Martino, R.; Morani, M.C. Wastewater Pump Control under Mechanical Wear. Water 2019, 11, 1210. [CrossRef]

24. Kong, L.; Lei, X.; Wang, H.; Long, Y.; Lu, L.; Yang, Q. A Model Predictive Water-Level Difference Control Method for Automatic Control of Irrigation Canals. Water 2019, 11, 762. [CrossRef]

25. Kong, L.; Quan, J.; Yang, Q.; Song, P.; Zhu, J. Automatic Control of the Middle Route Project for South-to-North Water Transfer Based on Linear Model Predictive Control Algorithm. Water 2019, 11, 1873. [CrossRef]

26. Carravetta, A.; Conte, M.C.; Fecarotta, O.; Ramos, H.M. Evaluation of PAT performances by modified affinity law. Procedia Eng. 2014, 89, 581-587. [CrossRef]

27. Derakhshan, S.; Nourbakhsh, A. Experimental study of characteristic curves of centrifugal pumps working as turbines in different specific speeds. Exp. Therm. Fluid Sci. 2008, 32, 800-807. [CrossRef]

Publisher's Note: MDPI stays neutral with regard to jurisdictional claims in published maps and institutional affiliations.

(C) 2020 by the authors. Licensee MDPI, Basel, Switzerland. This article is an open access article distributed under the terms and conditions of the Creative Commons Attribution (CC BY) license (http://creativecommons.org/licenses/by/4.0/). 